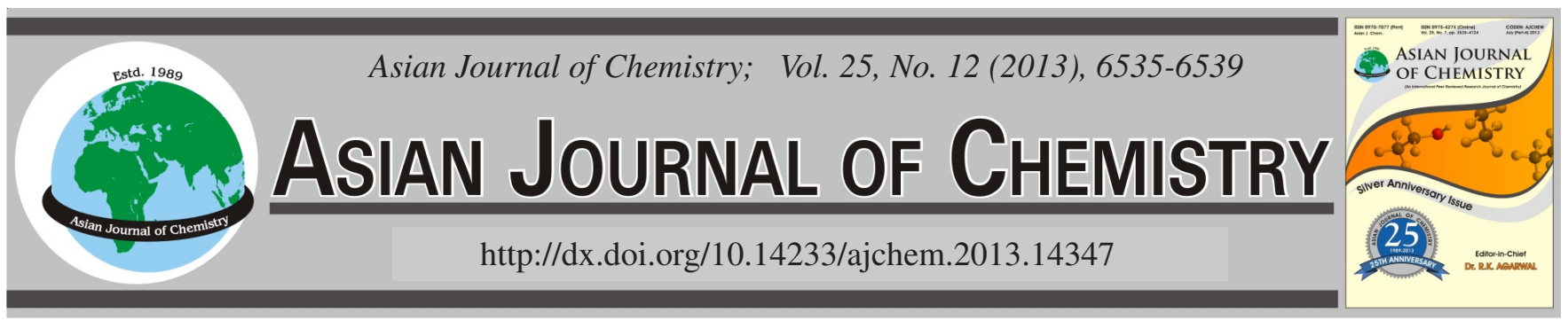

\title{
Enhanced Hydrogen and Methane Production from Sewage Sludge by Addition of Cornstalk in Two-Stage Fermentation Process
}

\author{
Di LiU ${ }^{1,2}, \operatorname{RU}$ Ying LI ${ }^{1, *}$, Min JI ${ }^{1, *}$ and YAN Ming CAI ${ }^{2}$
}

${ }^{1}$ School of Environmental Science and Engineering, Tianjin University, Tianjin, P.R.China

${ }^{2}$ Agro-Environmental Protection Institute of Ministry of Agriculture, Tianjin, P.R. China

*Corresponding authors: Tel/Fax: +86 22 27406057; E-mail: liruying@tju.edu.cn; jimin@ @ju.edu.cn

(Received: 20 July 2012;

Accepted: 20 May 2013)

AJC-13516

\begin{abstract}
Effects of cornstalk addition on hydrogen and methane production from sewage sludge in the two-stage fermentation process were investigated. Results of batch experiments showed that addition of cornstalk increased hydrogen production rate and hydrogen and methane yield of sewage sludge fermentation. At substrate concentration of $10 \mathrm{~g}$-volatile solid/L and the total solid ratio of $2: 1$ for cornstalk and sewage sludge, hydrogen and methane yields were 13.4 and $172.6 \mathrm{~mL} / \mathrm{g}$-volatile solid, respectively. At the hydrogen production stage in the fermentation of the mixture of cornstalk and sewage sludge, more than $80 \%$ of VFA product was acetate, which showed different VFA profile from hydrogen fermentation of sole cornstalk or sole sewage sludge. In the two-stage fermentation process, most of the energy produced was methane energy and hydrogen energy was only $0.3-2.8 \%$ of the total produced energy. Hydrogen yield, methane yield and total biogas energy increased with the proportion of cornstalk.
\end{abstract}

Key Words: Sewage sludge, Cornstalk, Fermentation, Hydrogen production, Methane.

\section{INTRODUCTION}

Sewage sludge is the product of wastewater treatment processes. Management of sewage sludge is one of the main environmental issues in China, since the amount of sludge has been increasing dramatically during the past decade. Sewage sludge is not only a pollutant, but also an available biomass resource. Anaerobic digestion can effectively utilize the bioenergy of sewage sludge, with the production of methane fuel. In this process, sewage sludge is first hydrolyzed and fermented into fatty acids and then further converted into acetate and hydrogen, both of which are lastly converted into methane ${ }^{1}$. However, the conventional anaerobic fermentation technology does not collect hydrogen, an important intermediate product during the fermentation process.

Hydrogen is a clean energy, producing only from water upon combustion, as well as being an industrial chemical with multiple applications ${ }^{2}$. Hydrogen has an energy yield of 122 $\mathrm{kJ} / \mathrm{g}, c a .2 .75$ times higher than those of hydrocarbons ${ }^{3}$. Recently, hydrogen fermentation from sewage sludge has drawn more and more attention ${ }^{4}$. However, hydrogen fermentation cannot degrade organics completely, producing a great amount of fatty acids, which can be converted into methane by methanogens ${ }^{5}$. Therefore, co-production of hydrogen and methane in a two-stage anaerobic fermentation process can increase energy conversion and substrates utilization efficien- cies. Researches on the two-stage hydrogen and methane production have been attempted using readily biodegradable substrates, such as glucose ${ }^{5}$, food waste ${ }^{6}$, potato $^{7}$ and stillage ${ }^{8}$ etc., whereas sewage sludge is generally used as inoculum and reports on two-stage hydrogen and methane fermentation from sewage sludge are limited.

Sewage sludge of most wastewater treatment plants in China has a relative low $\mathrm{C} / \mathrm{N}$ ratio of less than $5: 1$, which results in a low biogas yield in fermentation process. In China, lignocellulosic biomass is an abundant biomass resource produced during agricultural activities, with the annual yield of more than 0.7 billion tons, among which the amount of cornstalk is around 220 million tons ${ }^{9}$. The $\mathrm{C} / \mathrm{N}$ ratio of cornstalk is about 50:1, which is much higher than that of sewage sludge. Therefore, addition of cornstalk into sewage sludge can adjust the $\mathrm{C} / \mathrm{N}$ ratio of fermentation feedstock and thus enhance the biogas production in the anaerobic fermentation process. Most of organics in sewage sludge are microbial cellular materials wrapped by cell wall, which are difficult to be utilized directly. Also, direct fermentation of cornstalk is inefficient due to its complex structure with high crystallinity. Therefore, pretreatment of sludge and cornstalk biomass by diluted acid, alkali, or heat have been extensively studied to improve their fermentation efficiencies and alkaline pretreatment has been proved to be an effective method ${ }^{10-12}$. 
This study was conducted to investigate the effects of cornstalk addition on hydrogen and methane production from sewage sludge in the two-stage fermentation process. Cornstalk and sewage sludge were pretreated by alkali and mixed by different proportions to adjust $\mathrm{C} / \mathrm{N}$ ratio of fermentation substrates. Parameters examined included hydrogen and methane yields, hydrogen production rates, volatile fatty acids composition and energy analysis.

\section{EXPERIMENTAL}

Substrates used in this study includes sewage sludge and cornstalk waste. Sewage sludge was taken from secondary sedimentation tank of Ji Zhuangzi wastewater treatment plant in Tianjin, China. The sewage sludge contained $96 \%$ water and $4 \%$ total solids (TS) and $49.2 \%$ of total solid was volatile solids (VS). C/N ratio of sewage sludge was 4.3:1. Cornstalk was obtained from Shandong province, China, with a water content of $8 \%, \mathrm{VS} / \mathrm{TS}$ ratio of $92.9 \%$ and $\mathrm{C} / \mathrm{N}$ ratio of $53: 1$. The total solids of cornstalk contained $31.8 \%$ of cellulose, $19.5 \%$ of hemicellulose, $28.1 \%$ of lignose and $20.6 \%$ other components.

The activated sludge obtained from Ji Zhuangzi wastewater treatment plant was cultured under anaerobic condition for five days and used as seed sludge for methane production. The anaerobic sludge heated at $105^{\circ} \mathrm{C}$ for $0.5 \mathrm{~h}$ was used as seed sludge for hydrogen production. The VS/TS ratios of seed sludge for hydrogen and methane production stages were 48.2 and $46.7 \%$, respectively.

Experimental procedure: The substrates were pretreated before anaerobic fermentation. Cornstalk was first shredded into small pieces and those with particle size of $0.9 \mathrm{~mm}$ were selected by sieve for fermentation experiments. The shredded cornstalk was then immersed in $2 \% \mathrm{NaOH}$ solution at $50{ }^{\circ} \mathrm{C}$ for $48 \mathrm{~h}$. The sewage sludge was immersed in $\mathrm{NaOH}$ solution at $\mathrm{pH} 12$ at room temperature for $24 \mathrm{~h}$.

The experiments were carried out in $300 \mathrm{~mL}$ serum bottles filled with $150 \mathrm{~mL}$ of substrates. The pretreated cornstalk and sewage sludge were mixed by TS ratio of $2: 1,3: 2,1: 1,2: 3$, respectively and the sewage sludge without cornstalk addition served as control. Batch experiments were conducted in parallel at each TS ratio between cornstalk and sewage sludge. The initial substrates concentration in each bottle was $10 \mathrm{~g}$ $\mathrm{VS} / \mathrm{L}$. The initial $\mathrm{pH}$ was 7 and the seed sludge for hydrogen production was $0.25 \mathrm{~g}$ dry weight. Each bottle was purged by nitrogen gas for $15 \mathrm{~min}$ and then sealed by rubber stopper. The bottles were put in a shaker with shaking speed of 120 $\mathrm{rpm}$ and the temperature of the shaker was kept at $37^{\circ} \mathrm{C}$. After hydrogen production ceased, added seed sludge for methane production with dry weight of $0.74 \mathrm{~g}$ into each bottle and adjusted the $\mathrm{pH}$ to $\mathrm{pH} 7$. Each bottle was purged by nitrogen gas for $15 \mathrm{~min}$ again before sealing and then put in the shaker for methane fermentation under shaking speed of $120 \mathrm{rpm}$ and the temperature of $37^{\circ} \mathrm{C}$.

Methods of analysis: The volume of biogas produced in the bottle was measured using a glass syringe. Hydrogen and methane contents in the biogas were analyzed by a gas chromatograph (BEIFEN 3040, China) equipped with a thermal conductivity detector and a packed column (TDX-01, 2 m).
Argon was used as carrier gas with a flow rate of $35 \mathrm{~mL} / \mathrm{min}$. The temperature of column and injection port was $100^{\circ} \mathrm{C}$ and the detector temperature was $130{ }^{\circ} \mathrm{C}$.

The cumulative hydrogen/methane production can be calculated by the following equation:

$$
\mathrm{V}_{2}=\mathrm{V}_{1}+\mathrm{V}_{\mathrm{g}} \times \mathrm{C}_{2}+\mathrm{V}_{0} \times\left(\mathrm{C}_{2}-\mathrm{C}_{1}\right)
$$

where $V_{2}$ and $V_{1}$ represent the cumulative hydrogen/ methane production at the time $t_{2}$ and $t_{1}$, respectively $(\mathrm{mL}), \mathrm{C}_{2}$ and $\mathrm{C}_{1}$ the hydrogen/methane contents in the headspace of serum bottle at the time $t_{2}$ and $t_{1}$, respectively $(\%), V_{0}$ the volume of headspace $(\mathrm{mL}), \mathrm{V}_{\mathrm{g}}$ the volume of biogas produced in the bottle from time $t_{1}$ to $t_{2}$ measured by a glass syringe $(\mathrm{mL})$.

Volatile fatty acids (VFA) were analyzed by another gas chromatograph (SP6890, China) equipped with a hydrogen flame ionization detector and a $10 \mathrm{~m} \times 0.53 \mathrm{~mm}$ fused-silica capillary column (HP-FFAP). Nitrogen was used as carrier gas with a flow rate of $6 \mathrm{~mL} / \mathrm{min}$. The temperature of column and injection port was $200{ }^{\circ} \mathrm{C}$ and the detector temperature was $250^{\circ} \mathrm{C}$. TS and VS of sewage sludge and cornstalk were determined by standard methods ${ }^{13}$. Soluble protein in the liquid phase was measured by Lowry's method ${ }^{14}$.

Kinetic modeling: The cumulative hydrogen volume in the batch reactor followed the modified Gompertz equation ${ }^{15}$ :

$$
\mathrm{H}=\mathrm{P} \exp \left\{-\exp \left[\frac{\mathrm{R}_{\mathrm{m}} \mathrm{e}}{\mathrm{P}}(\lambda-\mathrm{t})+1\right]\right\}
$$

where $\mathrm{H}$ represents the cumulative hydrogen production $(\mathrm{mL})$, $\lambda$ the lag phase time (h), $\mathrm{P}$ the hydrogen production potential $(\mathrm{mL})$ and $\mathrm{R}_{\mathrm{m}}$ the maximum hydrogen production rate $(\mathrm{mL} / \mathrm{h})$. The values of $P, R_{m}$ and $\lambda$ for each experiment were determined by best fitting the hydrogen production data for eqn. 2 using Microsoft's software Excel 2003.

The hydrogen yield (mL/g-VS), maximum specific hydrogen production rate $(\mathrm{mL} / \mathrm{h} / \mathrm{g}-\mathrm{VS})$ and methane yield (mL/g-VS) were calculated by eqns. 3, 4 and 5, respectively.

$$
\text { Hydrogen yield }=\frac{\mathrm{H}}{\text { Total VS in feedstock }}
$$

Maximum specific hydrogen production rate

$$
=\frac{\mathrm{R}_{\mathrm{m}}}{\text { Total VS in feedstock }}
$$

$$
\text { Methane yield }=\frac{\text { Cumulative methane production }}{\text { total VS in feedstock }}
$$

\section{RESULTS AND DISCUSSION}

Hydrogen production: Cumulative hydrogen volumes and maximum hydrogen production rates at various TS ratios between cornstalk and sewage sludge (defined as and hereinafter called RS) were simulated by the modified Gompertz equation. Fig. 1 illustrates data of hydrogen yields and maximum specific hydrogen production rates calculated by eqns. 3 and 4 at different RS.

Fig. 1 shows that hydrogen yield increased with the cornstalk proportion in the mixed substrates. The hydrogen yield reached $13.4 \mathrm{~mL} / \mathrm{g}$-VS at RS of 2:1, which was more than 12 times higher than the control. The hydrogen yield for sewage 


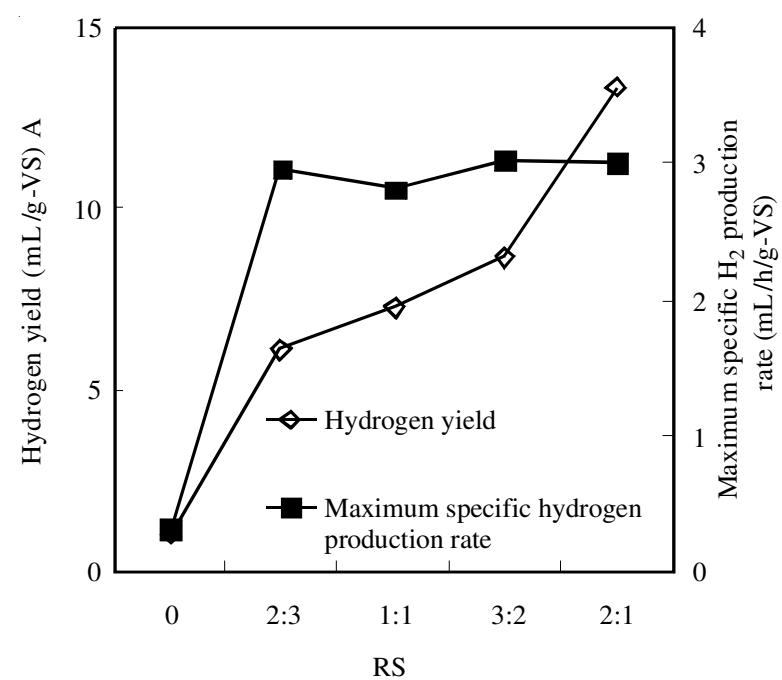

Fig. 1. Hydrogen yield and maximum specific hydrogen production rate at various RS

sludge fermentation without cornstalk addition (control) was $1.0 \mathrm{~mL} / \mathrm{g}-\mathrm{VS}$, which was higher than the reported $0.35 \mathrm{~mL} / \mathrm{g}$ VS for the raw sludge fermentation without pretreatment ${ }^{16}$. In a study of hydrogen production from sewage sludge and rice straw, no hydrogen production was observed for both raw sludge and heat-treated sludge ${ }^{17}$, suggesting the low hydrogen production potential for sole sludge fermentation. The maximum hydrogen yield of $13.4 \mathrm{~mL} / \mathrm{g}$-VS at RS of $2: 1$ in this study was comparable to the reported $10.8-14.8 \mathrm{~mL} / \mathrm{g}$-VS for co-digestion of rice straw and sewage sludge at RS of about $8: 1^{17}$.

Fig. 1 also shows that the maximum specific hydrogen production rates were closed to each other at various cornstalk proportions with the values of $2.96-3.03 \mathrm{~mL} / \mathrm{h} / \mathrm{g}-\mathrm{VS}$, which were considerably higher than the rate of control with a value of $0.31 \mathrm{~mL} / \mathrm{h} / \mathrm{g}$-VS. Results of a separate series of experiments showed that the maximum specific hydrogen production rate of the alkali-treated cornstalk was $1.93 \mathrm{~mL} / \mathrm{h} /$ g-VS, which was ca. $35 \%$ lower than those in the fermentation of mixed cornstalk and sewage sludge. This suggests that co-fermentation of cornstalk and sewage sludge was likely to increase the hydrogen production rate, compared to fermentation of sole cornstalk or sewage sludge.

In the hydrogen production stage, no methane production was observed for the fermentation of mixed substrates. However, fermentation of sole sludge produced both hydrogen and methane and the methane content in the biogas increased gradually during the whole hydrogen fermentation process. Further study for the reason of this aspect is warranted.

Methane production: After $21 \mathrm{~h}$, hydrogen production ceased. The $\mathrm{pH}$ of substrates was adjusted to $\mathrm{pH} 7$ and methaneproducing sludge was inoculated into each bottle for the methane production stage. Fig. 2 plots methane yields with time at RS values varying from 0 to 2 . Results show that methane yields increased with cornstalk proportion, with a maximum value of $172.6 \mathrm{~mL} / \mathrm{g}$-VS at RS of $2: 1$, which was 1.4 times of that for the RS of 0 . This maximum yield was also comparable to the reported $182 \mathrm{~mL} / \mathrm{g}-\mathrm{VS}$ for another alkali-treated sludge ${ }^{18}$.

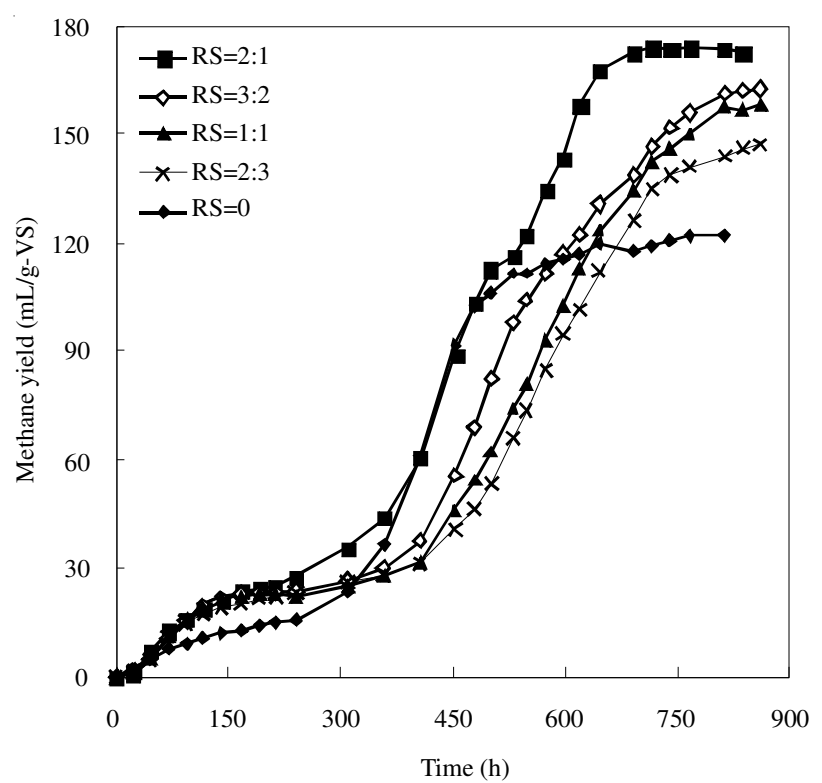

Fig. 2. Methane yield at various RS

Fig. 2 also shows that methane was produced at relatively higher rates in two periods during the whole methane fermentation stage, which were $0-150$ and $300-650 \mathrm{~h}$, respectively. In the first $0-150 \mathrm{~h}$, methane was produced rapidly without a noticeable lag phase and then gradually leveled off. At around $220 \mathrm{~h}$, methane started to be produced again and in the afterwards 300-650 h, methane was produced at the highest rates. This was different from methane production in a single-stage fermentation process, which experienced only one rapid biogas production period after a lag phase time ${ }^{19}$.

\section{Variation of volatile fatty acid}

Volatile fatty acid production in the hydrogen production stage: VFAs were important by-products in hydrogen fermentation process. Table- 1 shows the concentrations of total VFA and main components at various RS values. Results in Table-1 show that the total VFA concentration increased with cornstalk proportion in the substrates. This might be due to the relatively more soluble reducing sugar dissolved out from cornstalks during the alkali-pretreatment process for the substrates with higher cornstalk proportions. In the hydrogen fermentation process, hydrogen-producing bacteria preferentially utilized the soluble reducing sugar and thus produced more VFAs for those with more cornstalks in the substrates.

Table-1 shows that acetate was the main composition of VFA (82-84 \%), followed by butyrate (9-11\%) for the fermentation of mixed cornstalk and sewage sludge. This result was different from those of hydrogen fermentation of carbohydrates in many studies, in which more butyrate or comparable acetate and butyrate were detected in the VFA products ${ }^{20,21}$. However, for the hydrogen fermentation from sole sewage sludge, the main compositions of VFA product were acetate $(58.3 \%)$, propionate $(12.6 \%)$ and i-valerate $(14.3 \%)$ and very little butyrate $(5.2 \%)$ was detected. This result was similar to those of hydrogen fermentation from both untreated and various pretreated sludge ${ }^{16,22}$.

Many pathways have been proposed for hydrogen production according to the main fermentation products mainly 
TABLE-1

CONCENTRATIONS AND COMPOSITIONS OF VOLATILE FATTY ACID (VFA) AT THE END OF HYDROGEN PRODUCTION STAGE

\begin{tabular}{|c|c|c|c|c|c|c|c|c|}
\hline \multirow{2}{*}{ RS } & \multirow{2}{*}{ VFA (mg/L) } & \multicolumn{7}{|c|}{ VFA composition $(\%)$} \\
\hline & & Ethanol & Acetate & Propionate & $i$-Butyrate & Butyrate & $i$-Valerate & Valerate \\
\hline 0 & 444.0 & 0.2 & 58.3 & 12.6 & 6.0 & 5.2 & 14.3 & 3.4 \\
\hline $2: 3$ & 789.9 & 0.1 & 82.4 & 3.1 & 1.4 & 9.4 & 3.2 & 0.4 \\
\hline $1: 1$ & 930.5 & 1.5 & 83.9 & 2.1 & 1.0 & 9.0 & 2.2 & 0.4 \\
\hline $3: 2$ & 1073.0 & 1.3 & 84.2 & 2.4 & 0.5 & 10.0 & 0.9 & 0.7 \\
\hline $2: 1$ & 1568.1 & 1.4 & 84.2 & 1.3 & 1.1 & 10.9 & 0.9 & 0.2 \\
\hline
\end{tabular}

including acetate, butyrate and ethanol. However, some reactions may occur during fermentation tending to consume hydrogen with the production of other by-products, such as propionate $^{1}$, as shown in eqn. 6 . This might be one of the reasons of less hydrogen yield for the sole sewage sludge fermentation with more propionate produced.

$$
\mathrm{C}_{6} \mathrm{H}_{12} \mathrm{O}_{6}+2 \mathrm{H}_{2} \longrightarrow 2 \mathrm{CH}_{3} \mathrm{CH}_{2} \mathrm{COOH}+2 \mathrm{H}_{2} \mathrm{O}
$$

Volatile fatty acid variation in the methane production stage: As illustrated in Fig. 2, methane was produced at relatively higher rates in two periods, which were 0-150 and 300$650 \mathrm{~h}$, respectively. Fig. 3 illustrates the concentrations of various VFA compositions at the end of hydrogen production stage and cumulative methane volume in the $0-150 \mathrm{~h}$ of methane production stage. Fig. 3 shows that methane production in the first $0-150 \mathrm{~h}$ increased with cornstalk proportion in the substrates, as well as the total VFA and acetate concentrations produced in the hydrogen production stage. This result suggests that in the first 0-150 h, methanogens mainly utilized the VFAs produced in hydrogen production stage to produce methane without a lag phase.

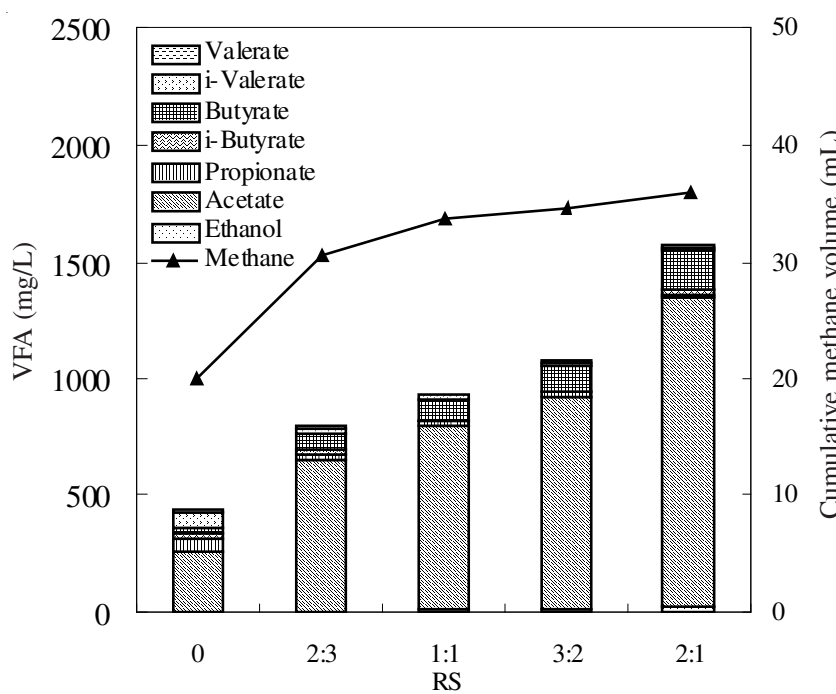

Fig. 3. Volatile fatty acid concentrations at the end of hydrogen production and cumulative methane volume in the first $0-150 \mathrm{~h}$ of methane production stage

Fig. 4 illustrates data of concentrations of soluble protein and main VFA compositions including acetate, butyrate and propionate at various fermentation stage for each RS condition. Fig. 4 shows that at the $220 \mathrm{~h}$ of methane production stage, concentrations of acetate and butyrate increased dramatically with the decrease of soluble protein and propionate increased slightly. This is likely to be the reason that methane started to be produced again at around $220 \mathrm{~h}$ and methane
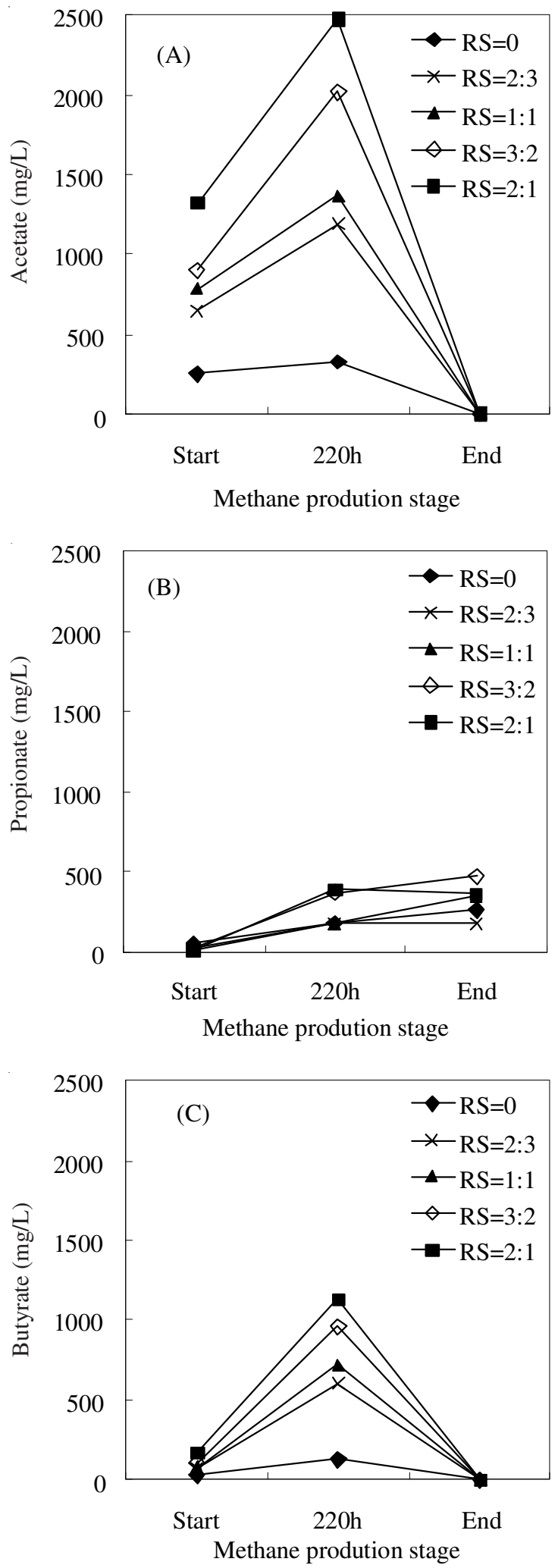
TABLE-2

HYDROGEN AND METHANE ENERGY PRODUCTION

\begin{tabular}{|c|c|c|c|c|c|c|c|}
\hline \multirow{2}{*}{ RS } & \multicolumn{3}{|c|}{ Hydrogen } & \multicolumn{3}{|c|}{ Methane } & \multirow{2}{*}{$\begin{array}{c}\text { Total energy } \\
(\mathrm{kJ} / \mathrm{g}-\mathrm{VS})\end{array}$} \\
\hline & Yield (mL/g-VS) & Energy $(\mathrm{kJ} / \mathrm{g}-\mathrm{VS})$ & Energy (\%) & Yield (mL/g-VS) & Energy $(\mathrm{kJ} / \mathrm{g}-\mathrm{VS})$ & Energy $(\%)$ & \\
\hline 0 & 1.0 & 0.01 & 0.31 & 122.1 & 4.27 & 99.69 & 4.29 \\
\hline $2: 3$ & 6.1 & 0.07 & 1.27 & 147.5 & 5.16 & 98.73 & 5.23 \\
\hline $1: 1$ & 7.3 & 0.08 & 1.42 & 158.5 & 5.55 & 98.58 & 5.63 \\
\hline $3: 2$ & 8.7 & 0.10 & 1.78 & 162.7 & 5.69 & 98.22 & 5.79 \\
\hline $2: 1$ & 13.4 & 0.17 & 2.80 & 172.6 & 6.04 & 97.20 & 6.21 \\
\hline
\end{tabular}

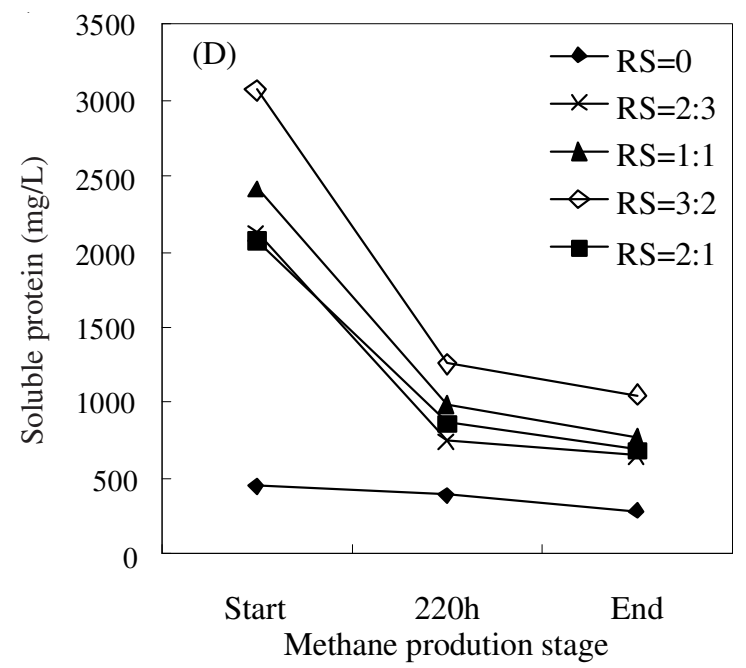

Fig. 4. Concentrations of acetate (A), propionate (B), butyrate (C) and soluble protein (D) at different periods of methane production stage for various RS

production rate increased considerably from the $300 \mathrm{~h}$ of this stage as shown in Fig. 2. At the end of methane production, acetate and butyrate were completely consumed and propionate was the main VFA composition.

Energy analysis: Table- 2 compiles data of hydrogen and methane yields, hydrogen and methane energy and their respective percentage in the total energy production. Hydrogen and methane energy were calculated according to their combustion heats of 890 and $286 \mathrm{~kJ} / \mathrm{mol}$, respectively ${ }^{23}$.

Table-2 shows that most of biogas energy produced in the two-stage fermentation process were from methane, whereas hydrogen energy only accounted for $0.3-2.8 \%$. In the sewage sludge fermentation, almost all of energy production was methane energy. In the co-fermentation of mixed cornstalk and sewage sludge, both total energy and hydrogen energy increased with cornstalk proportion. Table-2 also shows that total energy production was relatively higher when the percentage of hydrogen energy was higher. This suggests that improving hydrogen yield is likely to increase the total biogas energy recovery.

\section{Conclusion}

Addition of cornstalk in sewage sludge increased both hydrogen and methane yields in the two-stage fermentation process. At the substrate concentration of $10 \mathrm{~g}-\mathrm{VS} / \mathrm{L}$ and TS ratio of 2:1 between cornstalk and sewage sludge, hydrogen and methane yields were 13.4 and $172.6 \mathrm{~mL} / \mathrm{g}$-VS, respectively, which were respective around 13 and 1.4 times of those for sewage sludge fermentation. Acetate was the main composition of VFA products in hydrogen production stage. Methane was produced at relatively higher rates in two periods, which were $0-150$ and $300-650 \mathrm{~h}$, respectively. In the first 0-150 h, methanogens mainly utilized the VFAs produced in hydrogen production stage to produce methane without a lag phase and methane production rate increased considerably at around 300 $\mathrm{h}$ due to VFA accumulation by hydrolysis. Most of biogas energy produced in the two-stage fermentation process were from methane, whereas hydrogen energy only accounted for $0.3-2.8 \%$. Both total energy and hydrogen energy production increased with cornstalk proportion.

\section{ACKNOWLEDGEMENTS}

The authors are grateful to the financial support from the National High Technology Research and Development Program (863 Program) (Project No. SS2012AA063502) and the Open Fund of Key Laboratory of Original Agro-environment Quality of Ministry of Agriculture and Tianjin Key Laboratory of Agro-environment and Agro-product Safety.

\section{REFERENCES}

1. C.L. Li and H.H.P. Fang, Crit. Rev. Environ. Sci. Technol., 37, 1 (2007).

2. H.H.P. Fang, R.Y. Li and T. Zhang, Environ. Technol., 32, 1279 (2011).

3. R.Y. Li and H.H.P. Fang, Crit. Rev. Environ. Sci. Technol., 39, 1081 (2009).

4. Y. Zhao, Y. Chen, D. Zhang and X. Zhu, Environ. Sci. Technol., 44, 3317 (2010).

5. B. Xie, J. Cheng, J. Zhou, W. Song and K. Cen, Int. J. Hydrogen Energy, 33, 5006 (2008).

6. C.F. Chu, Y.Y. Li, K.Q. Xu, Y. Ebie, Y. Inamori and H.-N. Kong, Int. J. Hydrogen Energy, 33, 4739 (2008).

7. H. Zhu, A. Stadnyk, M. Beland and P. Seto, Bioresour. Technol., 99, 5078 (2008).

8. G. Luo, L. Xie, Q. Zhou and I. Angelidaki, Bioresour. Technol., 102, 8700 (2011).

9. Y. Xing, S.Q. Fan, J.N. Zhang, Y.-T. Fan and H.W. Hou, Int. J. Hydrogen Energy, 36, 12770 (2011).

10. D. Zhang, Y. Chen, Y. Zhao and X. Zhu, Environ. Sci. Technol., 44, 4802 (2010).

11. A.J. Ward, P.J. Hobbs, P.J. Holliman and D.L. Jones, Bioresour. Technol,, 99, 7928 (2008).

12. Y.-T. Fan, Y. Xing, H.-C. Ma, C.-M. Pan and H.-W. Hou, Int. J. Hydrogen Energy, 21, 33 (2008).

13. APHA: Standard Methods for the Examination of Water and Wastewater, Washington, DC (2005).

14. O.H. Lowry, N.J. Rosebrough and A.L. Farr, J. Biol. Chem., 193, 265 (1951).

15. J.J. Lay, Y.Y. Li and T. Noike, J. Environ. Eng., 124, 730 (1998).

16. B. Xiao and J. Liu, J. Hazard. Mater., 168, 163 (2009).

17. M. Kim, Y. Yang, M.S. Morikawa-Sakura, Q. Wang, M.V. Lee, D.-Y. Lee, C. Feng, Y. Zhou andZ. Zhang, Int. J. Hydrogen Energy, 4, 37 (2012).

18. C.H. Ting and D.J. Lee, Int. J. Hydrogen Energ., 32, 677 (2007).

19. S. Luostarinen, S. Luste and M. Sillanpää, Bioresour. Technol., 100, 79 (2009).

20. H.H.P. Fang and H. Liu, Bioresour. Technol., 82, 87 (2002).

21. H.H.P. Fang, C. Li and T. Zhang, Int. J. Hydrogen Energy, 31, 683 (2006).

22. L. Guo, X.M. Li, X. Bo, Q. Yang, G.-M. Zeng, D.-X. Liao and J.-J. Liu, Bioresour. Technol., 99, 3651 (2008).

23. T.D. Distefano and A. Palomar, Water Res., 44, 2583 (2010). 